\title{
Academic snakes and ladders
}

\author{
The Chicago Guide to Landing a Job in \\ Academic Biology \\ by $\mathrm{C}$. Ray Chandler, Lorne M. Wolfe and \\ Daniel E. L. Promislow \\ University of Chicago Press: 2007.176 pp. \$14
}

\section{Pamela A. Silver}

At one time, academic biology was the province of those willing to work long, irregular hours and to wear threadbare jackets with elbow patches. Overachievers with an interest in biology generally went into medicine. Academic jobs were few, but demand was low. With the advent of biotechnology, the sequencing of the human genome, and overhead charges on government grants, faculty positions in biology have now transformed from a calling into a well-paid career. It was perhaps inevitable that 'how to' books would materialize to guide hungry job-seekers in what has become a competitive market.

The Chicago Guide to Landing a Job in Academic Biology is a nuts-and-bolts book, full of practical advice such as how to construct an application that won't be thrown out, how to give a seminar, and how to complete the interview process successfully. Some will profit from its advice and will be glad that they read the book. Others may be disturbed by its implicit message that landing a job in academia requires a careerist mindset and not just raw brilliance.

The book has a limited target audience - the fraction of graduate students and postdoctoral fellows that actually want to carry on in academic research. Starting with the assumption that the reader wants an academic job, the authors go into great detail about how to get one. What should you put in your cover letter with your job application? What should you wear at your interview? How many jobs should you apply for? The advice is sensible, being based on years of reading flawed job applications and watching candidates make fatal errors.

For someone who has already been through the process, it is hard to read the book without pondering the bigger questions. Is this really the best process for choosing faculty members? Does it select for the best researchers and teachers, or does it generate careerists who are good at applying for jobs? Does it favour advisers who are willing to write exaggerated letters of recommendation, thereby gaining a reputation as a good careerpromoter? In a training process that may take six years of graduate school and four years as a postdoctoral fellow, whose interests are really being served?

As the authors point out, a biologist undergoes a lengthy apprenticeship that rarely includes advice on training for a job per se. Speculating why this should be so is beyond the scope of the book. The answer may be that for an adviser to discuss the issue in any detail is like a parent talking to a child about their mid-life crisis. The job application process can itself be embarrassing - many applicants are unsuccessful and the present system breeds conservatism. More to the point, any realistic discussion on the topic should also consider unfairness, bad luck, poor choices and compromise. A book that simply describes the mechanics puts the onus on the next generation to refocus the process in a way that nurtures excitement about the unanswered questions in the biological sciences.

Pamela A. Silver is professor of systems biology at Harvard Medical School, 200 Longwood Avenue, Boston, Massachusetts 02115, USA.

\section{EVENT}

\section{Experiment-a-thon}

Matt Brown

A giant sombrero lurks in the undergrowth of London's

Kensington Gardens. Inside, a conical auditorium resonates with strange noises and good vibrations. The Serpentine Gallery's summer pavilion is gearing up for a 24-hour 'experiment-a-thon'.

The pavilion is an annual tradition. Leading architects with no previous commissions in the United Kingdom take a turn at designing the temporary venue. Alumni include Zaha Hadid (2000), Daniel Libeskind (2001) and Oscar Niemeyer (2003).

This year's steel and plywood structure is the work of Norwegian architect Kjetil Thorsen and Danish-Icelandic artist Ólafur Elíasson, whose installation 'The Weather Project' filled the Turbine Hall of London's Tate Modern gallery in 2003. The duo's pavilion has a spiral ramp around the outside, leading to a peaked roof designed to amplify sound. The Serpentine Gallery is renowned for filling its edgy summer structure with original events. This season, the emphasis

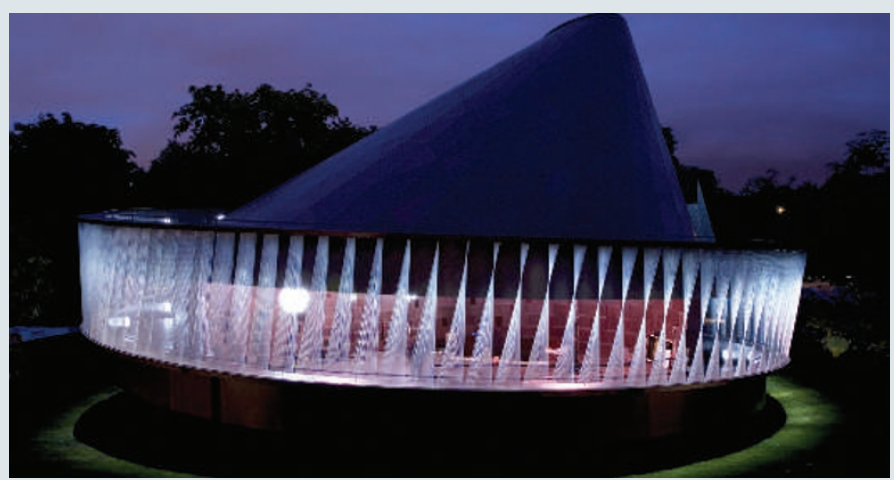

has been on 'experiments' - in which scientists, artists and architects exchange ideas from their fields with the public in Friday night 'laboratories'. These have included the debut performance of a new type of electric violin, and the pavilion itself played as an instrument. They are warm-up acts for the forthcoming all-nighter.

This weekend, around 30 performers, including autism researcher Simon Baron-Cohen and musician Brian Eno, will entertain and educate beneath the pavilion's strange geometries from midday on Saturday to midday on Sunday.

\section{Those planning to sit through the} whole night can rest assured: the coffee is excellent. A similar event in Berlin follows next month.

Olaf Blanke of the Swiss Federal Institute of Technology in Lausanne will demonstrate his recent headline-making video technology for simulating out-of-body experiences. Other experiments deal with phantom limbs, colour vision and Capgras syndrome the belief that close acquaintances have been replaced by impostors. Perception is an underlying theme. "Each experiment explores how the brain simplifies stimuli into a stable impression," explains participant Israel Rosenfield from the City University of New York.

"We're building on the success of last year's 24-hour interview marathon," says Hans Ulrich Obrist, co-director of exhibitions and programmes at the Serpentine Gallery. In Rem Koolhaas's 2006 pavilion, Obrist conducted a series of conversations with prominent Londoners. "A certain audience attends science events, another attends arts events; we hope to attract both."

Matt Brown is the editor of Nature Network London http://network. nature.com/london.

The Experiment Marathon begins at noon on 13 October. A second part takes place in Berlin on 9 November. 